\title{
VOC deep oxidation over Pt catalysts using hydrophobic supports
}

\author{
Jeffrey Chi-Sheng Wu*, Tai-Yuan Chang \\ Department of Chemical Engineering, National Taiwan University, Taipei 10617, Taiwan
}

\begin{abstract}
The active hydrophobic-supported Pt catalysts were synthesized for VOC deep oxidation at low temperature (less than $200^{\circ} \mathrm{C}$ ). The destruction of VOC could cost less at lower temperature due to less energy consumption. The advantage using hydrophobic support was that moistures from atmosphere and oxidation would not be adsorbed on the surface. Thus the active sites would not be cloaked and catalyst activity could be maintained, especially at low temperature. The hydrophobicity of supports was characterized by wetting angles. Porous SDB (styrene divinylbenzene copolymer) was found near $113^{\circ}$, indicating high hydrophobicity. Three Pt catalysts were prepared on SDB and activated carbons by incipient wetness method. Specific surface areas were measured by nitrogen adsorption. The thermal stability of SDB catalyst was examined by TGA, and found no degradation below $200^{\circ} \mathrm{C}$ in air. The surface compositions of catalysts were analyzed by EDS. XRD showed that Pt was well dispersed on supports after hydrogen reduction at $160^{\circ} \mathrm{C}$. The chemical states of Pt were investigated by XPS, and suggested that the oxidized $\mathrm{Pt}^{\mathrm{IV}}$ might be the active sites in the reaction. The deep oxidation of toluene/air mixture was carried out to test the activity of catalysts. Pt/SDB showed the highest activity among the catalysts and could completely oxidize $90 \mathrm{ppm}$ toluene/air at VHSV $=21000 \mathrm{~h}^{-1}, 150^{\circ} \mathrm{C}$. Redox mechanism was proposed to reveal the enhanced kinetic rates. The results suggested that the rate of toluene oxidation might be enhanced due to the fact that water, one of the products, was expelled from the hydrophobic surface. (C) 1998 Elsevier Science B.V. All rights reserved.
\end{abstract}

Keywords: VOC; Catalytic oxidation; Pt catalyst; Hydrophobic supports; SDB; Activated carbon; Toluene

\section{Introduction}

Catalytic oxidation is one of the most important methods for VOC (volatile organic compounds) destruction. In order to cut down the energy consumption, reaction temperature is required to be as low as possible. VOC can be oxidized over a catalyst at a temperature much lower than those of thermal oxidation. Supported Pt alumina and other metal oxides are typical catalysts for such applications and has been

\footnotetext{
*Corresponding author. Tel.: 008862 3631994; fax: 008862 362 3040; e-mail: cswu@ccms.ntu.edu.tw
}

studied widely [1]. Hegedus et al. [2] found that the conversions of CO oxidation were decreased near $10 \%$ over Pt/alumina catalyst when water vapor was introduced in feed stream. Deverino and Laine [3] also found that $\mathrm{CO}$ oxidation was significantly inhibited by the presence of water over the $\mathrm{CuO} / \mathrm{Al}_{2} \mathrm{O}_{3}$ and $\mathrm{CuCr}_{2} \mathrm{O}_{4} / \mathrm{Al}_{2} \mathrm{O}_{3}$ catalysts. Although the reason of negative water effect was not clear, the catalyst might be cloaked and the activity was reduced. Chuang et al. [4] compared the oxidation of several VOC compounds (BTX, methanol, and formaldehyde) over Pt hydrophilic and hydrophobic catalysts, and found that complete oxidation could be achieved at much lower 
temperatures using hydrophobic supports. At low temperature, the water vapor generated from VOC oxidation can be easily condensed in the micro/meso pores due to hydrophilicity. In addition, ambient air usually contains water vapor. The activity of catalysts may be varied due to the changing humidity. Hydrophobic catalysts can avoid such a problem. Furthermore, organic compounds are more readily adsorbed on the hydrophobic surface, such as activated carbons. The concentration of local adsorbed hydrocarbons is increased and water is expelled from the active sites. The oxidation rate is, thus, enhanced.

The applications of hydrophobic catalysts had been studied recently [4-7]. There were many new applications to be explored, for example, catalytic reactions in aqueous phase, combustible gases sensor, etc. The destruction of VOC at low temperature was only one of the many applications for hydrophobic supported Pt catalysts. The objective of this study was to develop VOC catalysts which could maintain/enhance the activity at low temperature to save energy. Our effort was focused on the characteristics and enhanced effect of hydrophobic supports in the catalytic oxidation of toluene.

\section{Experimental}

Porous SDB (styrene divinylbenzene copolymer) was used as support for its high hydrophobicity. It was obtained from K.T. Chuang, University of Alberta, Canada. Activated carbon was used widely as adsorbent to remove VOC. So, activated carbon (Aldrich) was also chosen as support for comparison. The original activated carbon was heated at $400^{\circ} \mathrm{C}$ in $\mathrm{N}_{2}$ stream for $1 \mathrm{~h}$ to remove adsorbed contaminants before use (assigned as AC01). Such activated carbon was found to contain $\mathrm{SiO}_{2} / \mathrm{Al}_{2} \mathrm{O}_{3}$ from EDS (energy dispersive X-ray spectroscopy) analysis. A batch of activated carbon was further rinsed with $40 \% \mathrm{HF}$ for $24 \mathrm{~h}$ in order to remove $\mathrm{SiO}_{2} / \mathrm{Al}_{2} \mathrm{O}_{3}$, then thoroughly washed with distilled water and dried at room temperature (assigned as AC03). The hydrophobicities of supports were denoted by wetting angles. The surface tension of water was measured on the supports (powder form). Then, the wetting angles were calculated from the measured surface tension based on Bröckel and Löffler method [8].
Platinum salt, $\mathrm{H}_{2} \mathrm{PtCl}_{6} \cdot x \mathrm{H}_{2} \mathrm{O}$, was purchased from Aldrich with $\sim 40 \mathrm{wt} \%$ of platinum. Typically, nearly $0.375 \mathrm{~g}$ of $\mathrm{H}_{2} \mathrm{PtCl}_{6} \cdot x \mathrm{H}_{2} \mathrm{O}$ was dissolved in $5 \mathrm{ml}$ methanol as a precursor solution for $5 \mathrm{~g}$ of catalyst. Catalysts (Pt/AC01, Pt/AC03 and Pt/SDB) with ca. $3 \mathrm{wt} \% \mathrm{Pt}$ were prepared by incipient wetness method. After impregnation, the catalysts were dried at ambient temperature overnight. The thermal stabilities of SDB and Pt/SDB were tested by TGA (thermogravimetric analysis), found stable below $200^{\circ} \mathrm{C}$ (see Section 3). The ceiling of thermal temperatures applied to $\mathrm{Pt} / \mathrm{SDB}$ was thus limited to $160^{\circ} \mathrm{C}$ for extra margin. For equal comparison, all catalysts were thus reduced at $160^{\circ} \mathrm{C}$ for $1 \mathrm{~h}$ with $3^{\circ} \mathrm{C} \mathrm{min}{ }^{-1}$ from room temperature under $20 \% \mathrm{H}_{2} / \mathrm{N}_{2}$ flow, then stored in a desiccator for later use.

Nitrogen BET method was used to measure the surface area of catalysts. The surface compositions of catalyst were analyzed by EDS. Platinum dispersion was inspected by XRD (X-ray diffraction). XPS (Xray photoelectron spectroscopy) was used to exhibit the chemical states of Pt.

Fig. 1 shows the schematic of reactor system. Toluene/air mixture was chosen to represent one of the VOC pollutants. The toluene vapor was carried by air from a saturator filled with liquid toluene. The concentrations of toluene were 90 and $442 \mathrm{ppm}$, which were adjusted by the temperature of saturator and mixed air flow rate. The reactions were performed at the temperature ranging from $90^{\circ} \mathrm{C}$ to $210^{\circ} \mathrm{C}$ except for $\mathrm{Pt} / \mathrm{SDB}$, which was limited to $160^{\circ} \mathrm{C}$. Catalyst $(0.25-0.5 \mathrm{~g})$ was packed in a straight-tube Pyrex reactor with $16 \mathrm{~mm}$ i.d. A thermocouple was placed in the center of catalyst bed to record reaction temperature and also used to control the furnace. The catalysts were reduced by hydrogen again in the reactor at $160^{\circ} \mathrm{C}$ before performing VOC oxidation. The reactant flows were adjusted to the VHSV (volume hour space velocity) of $12000-23000 \mathrm{~h}^{-1}$ under atmospheric pressure. Typically, the reaction temperature started from low to high, and the accumulated run time was $30-40 \mathrm{~h}$ for one catalyst. Both reactants and products were measured by an on-line GC. Major products were found $\mathrm{CO}_{2}$ and $\mathrm{H}_{2} \mathrm{O}$ only. Other hydrocarbons were almost negligible in most experimental conditions. Thus, the conversion was calculated based on toluene consumption. 


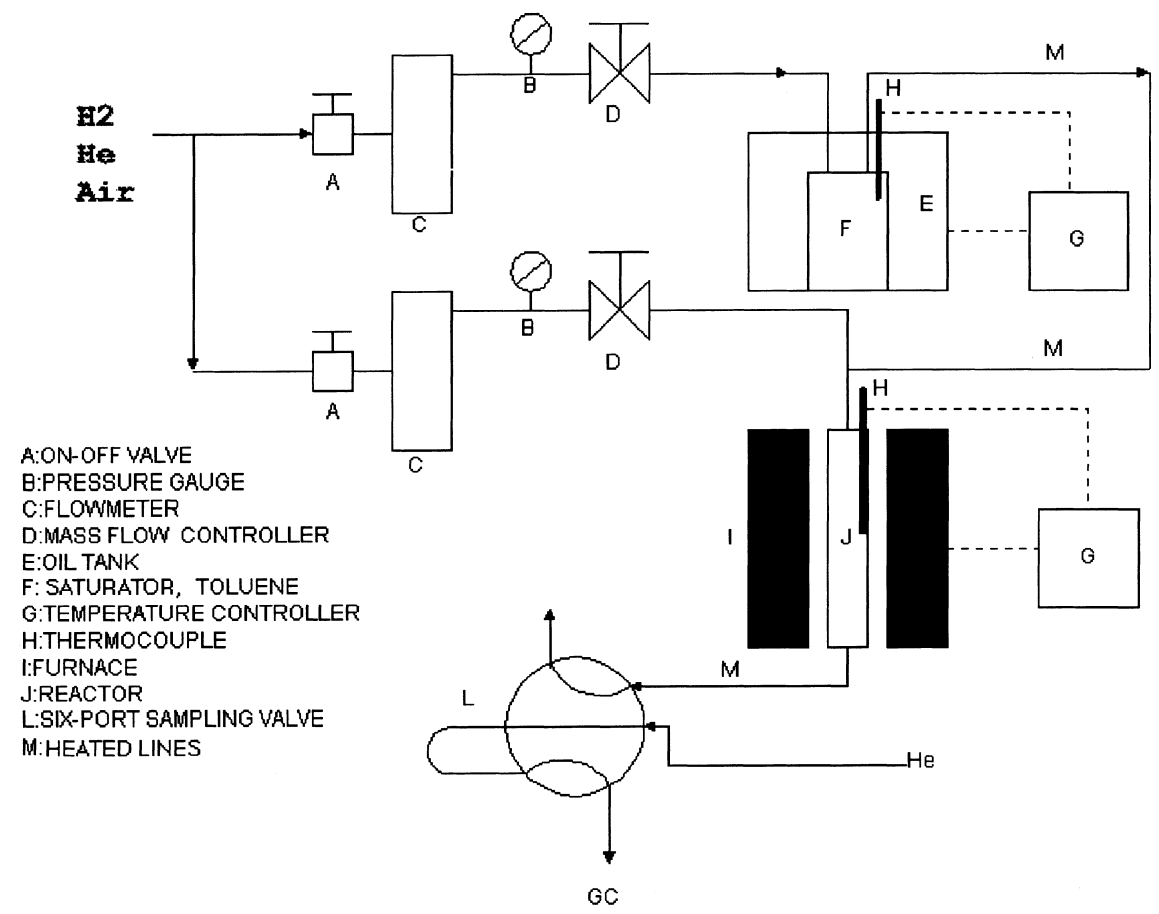

Fig. 1. Schematic diagram of reactor system.

\section{Results and discussion}

Fig. 2 shows the thermal stability of SDB and Pt/ SDB in air by TGA. Significant weight loss was observed at temperatures above $300^{\circ} \mathrm{C}$ indicated that SDB might be decomposed/oxidized in air. SDB alone was more stable than Pt/SDB. The oxidation of polymeric SDB could be accelerated by Pt above $300^{\circ} \mathrm{C}$. However, the Pt/SDB should be stable at least below $200^{\circ} \mathrm{C}$. Therefore, the thermal temperature applied to $\mathrm{Pt} / \mathrm{SDB}$ was limited below $160^{\circ} \mathrm{C}$ to ensure no degradation of SDB.

EDS elemental analysis are shown on Figs. 3-5. The original activated carbon (Pt/AC01) contained $\mathrm{SiO}_{2} / \mathrm{Al}_{2} \mathrm{O}_{3}$. After the HF treatment, the $\mathrm{SiO}_{2} / \mathrm{Al}_{2} \mathrm{O}_{3}$ of $\mathrm{Pt} / \mathrm{AC} 03$ was almost un-detected by EDS. Platinum was clearly observed on the spectra of all catalysts. Small amount of chlorine was still found in all catalysts since the precursor $\left(\mathrm{H}_{2} \mathrm{PtCl}_{6}\right)$ contained chlorine. The reduction temperature was limited to $160^{\circ} \mathrm{C}$ which might be not enough to remove chlorine as $\mathrm{HCl}$.

Table 1 lists the total surface areas and wetting angles of catalysts. The wetting angle of SDB was

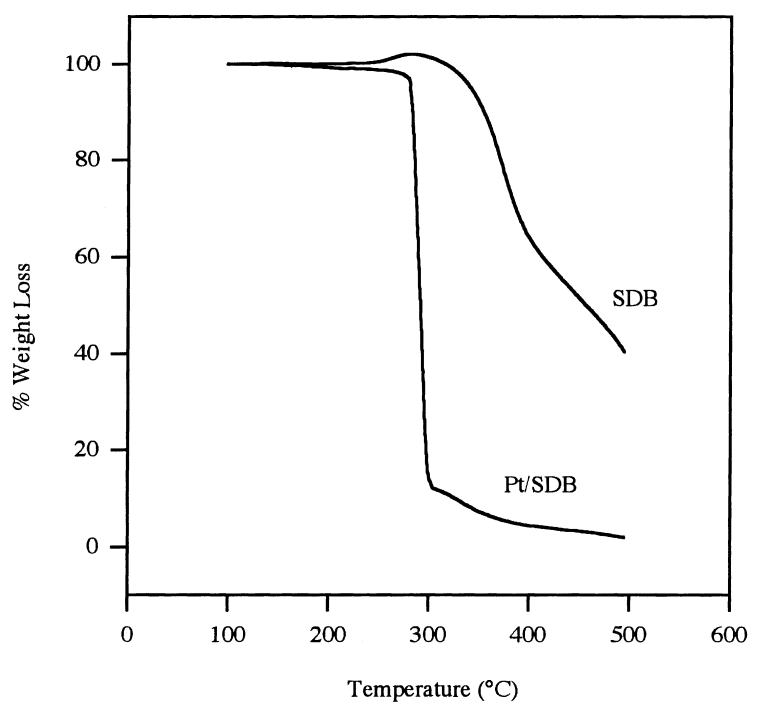

Fig. 2. Thermal stabilities of SDB and Pt/SDB by TGA.

$109-117^{\circ}$ indicating the highest hydrophobicity among the supports. The wetting angle of AC01 was $29-35^{\circ}$ showing less hydrophobic surface. The 


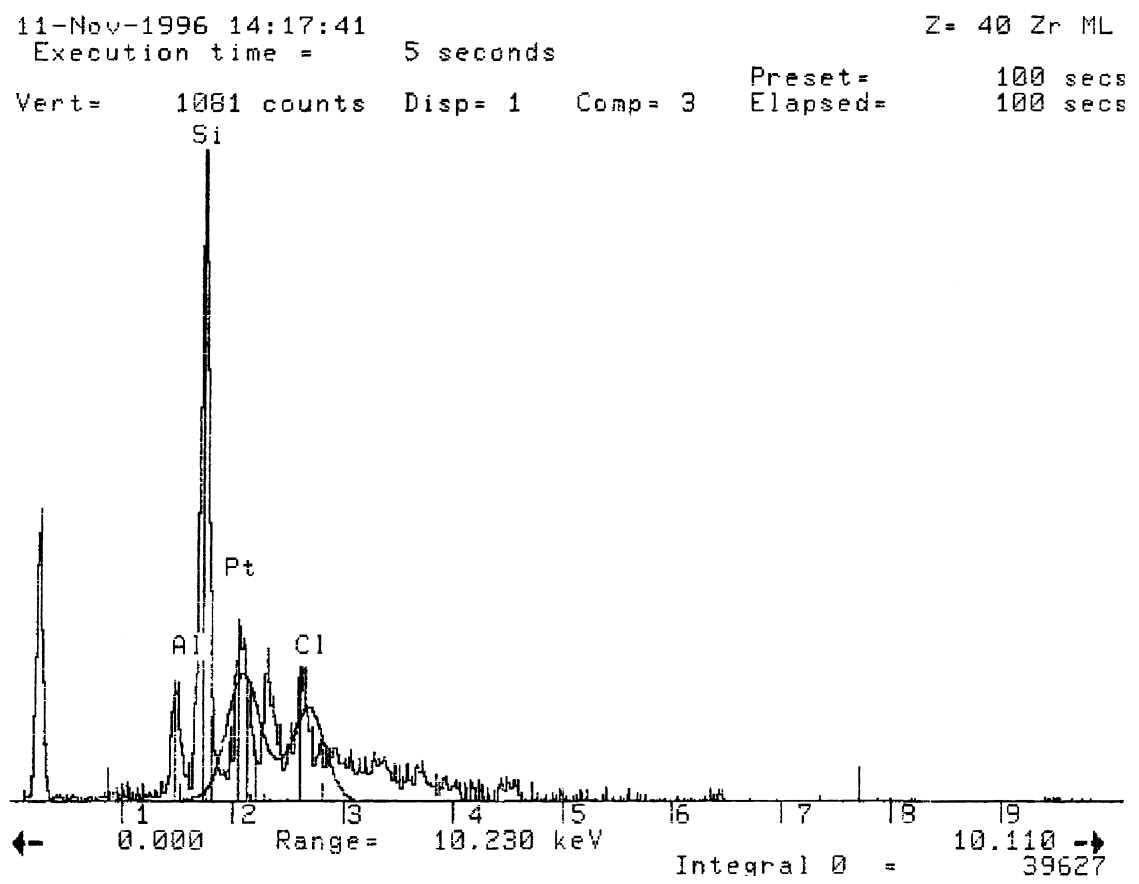

Fig. 3. EDS composition analysis of Pt/AC01.

22-Apr-1997 14:35:08

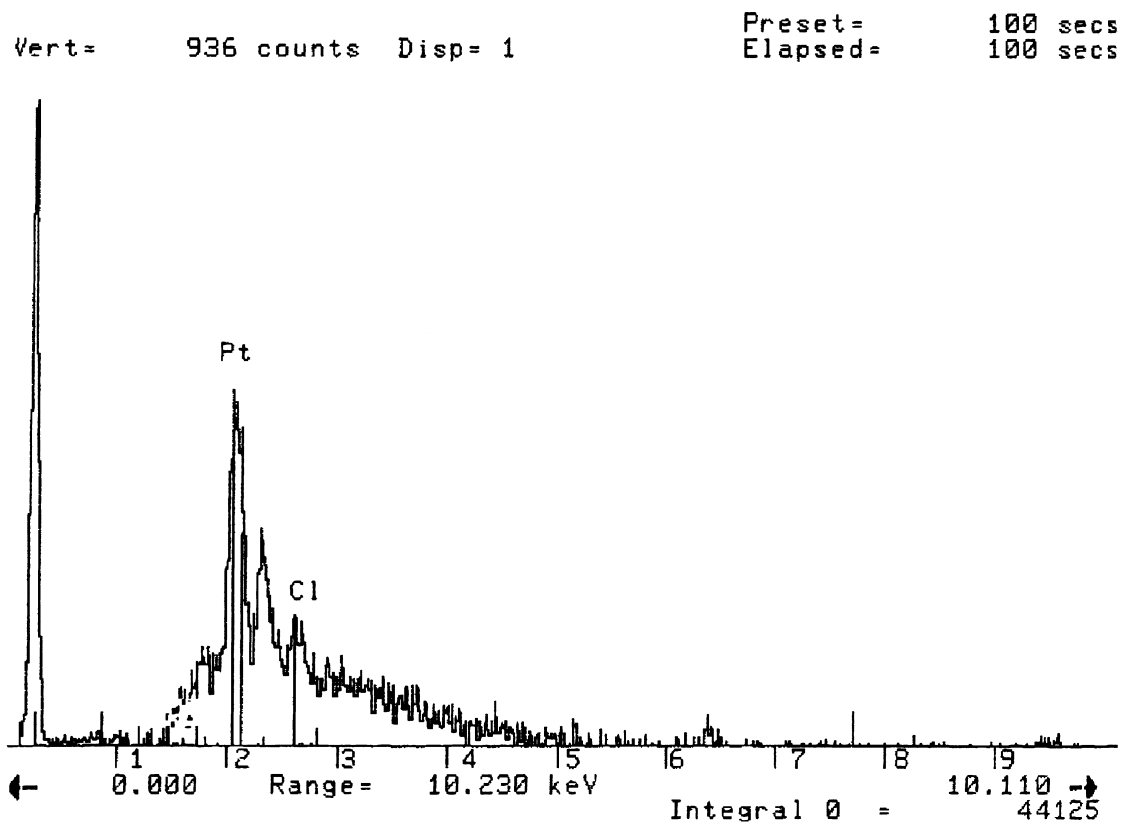

Fig. 4. EDS composition analysis of Pt/AC03. 


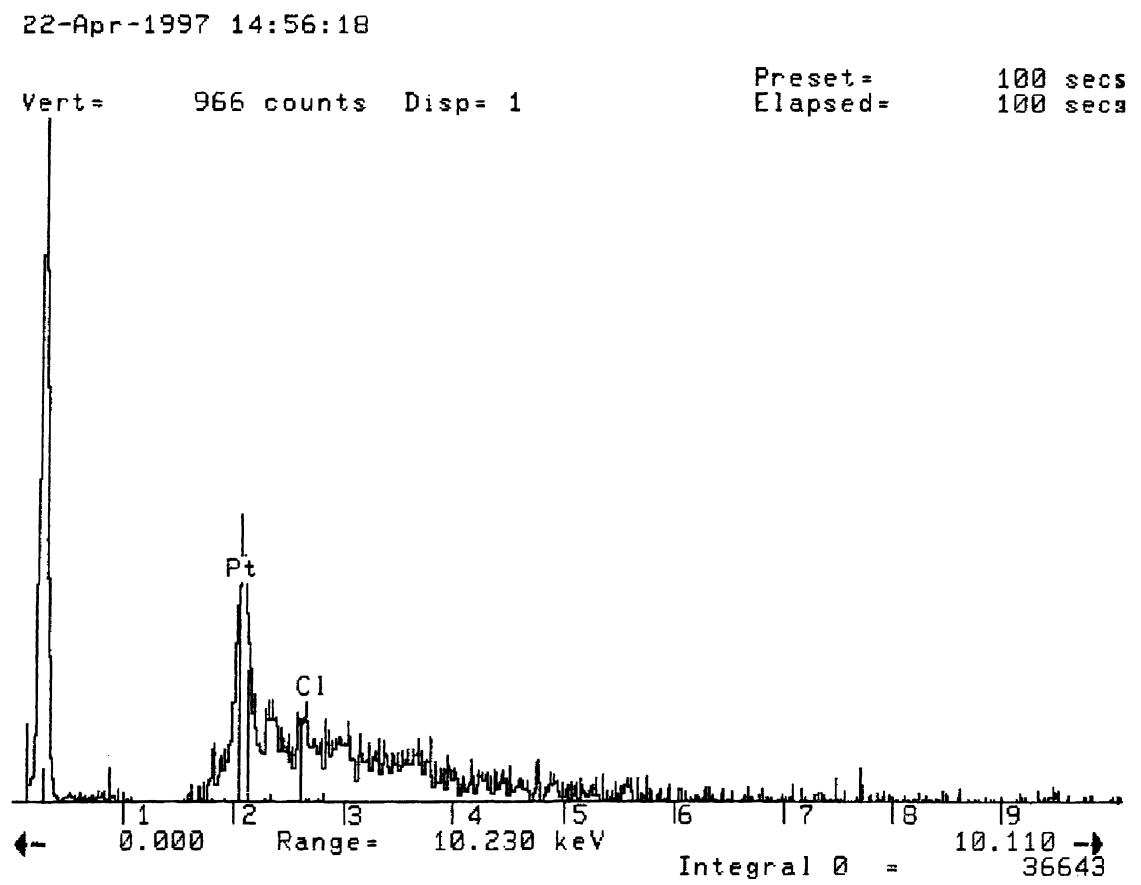

Fig. 5. EDS composition analysis of Pt/SDB.

Table 1

Characteristics of supports and Pt catalysts

\begin{tabular}{llll}
\hline Supports & SDB & AC01 & AC03 \\
\hline Wetting angle $\left({ }^{\circ}\right)$ & $109-117$ & $29-35$ & $50-55$ \\
Specific area $\left(\mathrm{m}^{2} \mathrm{~g}^{-1}\right)$ & 519 & 410 & 779 \\
& & & \\
Fresh Catalyst & & Pt/AC01 & Pt/AC03 \\
Specific area $\left(\mathrm{m}^{2} \mathrm{~g}^{-1}\right)$ & 497 & 502 & 713 \\
\hline
\end{tabular}

${ }^{\mathrm{a}} \mathrm{H}_{2}$ reduced at $160^{\circ} \mathrm{C}$.

wetting angle of AC03 increased from $29-35^{\circ}$ to 50 $55^{\circ}$ suggested that the hydrophobicity of activated carbon was improved by eliminating $\mathrm{SiO}_{2} / \mathrm{Al}_{2} \mathrm{O}_{3}$. The total surface area of Pt/SDB and Pt/AC01 was 497 and $502 \mathrm{~m}^{2} \mathrm{~g}^{-1}$, respectively. The surface area of $\mathrm{Pt} / \mathrm{AC} 03$ was $713 \mathrm{~m}^{2} \mathrm{~g}^{-1}$ after AC01 treated with $40 \%$ $\mathrm{HF}$. The acquired area might be due to extra micro/ meso pores created by removing $\mathrm{SiO}_{2} / \mathrm{Al}_{2} \mathrm{O}_{3}$.

The Pt dispersion can be qualitatively indicated by the particle size from the XRD spectra. The XRD spectra of fresh catalysts are shown in Fig. 6. The strongest Pt peak was at $2 \theta=39.5^{\circ}$. The Pt peak was

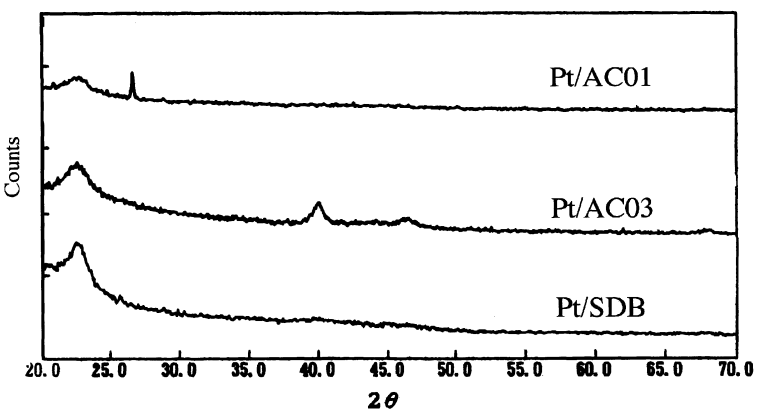

Fig. 6. XRD spectra of fresh catalysts.

clearly found for Pt/AC03 while no peak was observed for $\mathrm{Pt} / \mathrm{SDB}$ and $\mathrm{Pt} / \mathrm{AC} 01$. This implied that the platinum was well dispersed on Pt/SDB and Pt/AC01. The dispersion of $\mathrm{Pt} / \mathrm{ACO} 3$ was not as high as those of $\mathrm{Pt} / \mathrm{SDB}$ and Pt/AC01. The XRD spectra of used catalysts are shown in Fig. 7. The $\mathrm{Pt}$ peaks $\left(2 \theta=39.5^{\circ}\right.$ and $\left.47^{\circ}\right)$ observed for all catalysts indicated that Pt clusters were enlarged. The sintering of platinum was substantial after $30-40 \mathrm{~h}$ of toluene oxidation. The peaks of Pt/SDB were higher indicating 


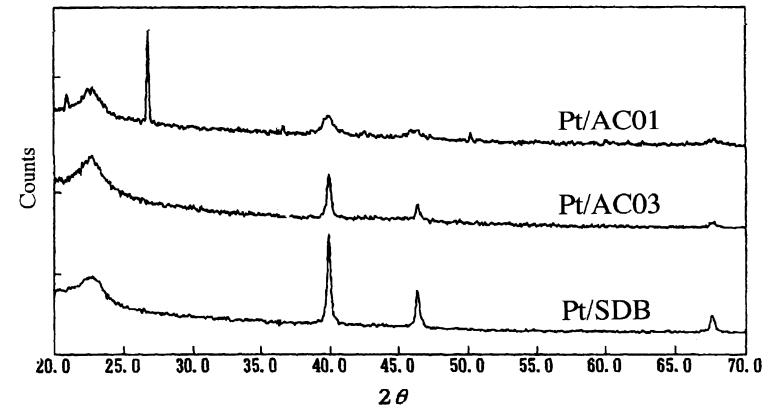

Fig. 7. XRD spectra of used catalysts.

platinum sintering was more severe even the reaction temperature was restricted below $160^{\circ} \mathrm{C}$. The migration of Pt particles could be higher on the surface of SDB, and the sticking force between Pt and SDB might be weaker than that of activated carbons.

The oxidation was initially carried out for the higher toluene concentration in air stream. However, ignition phenomenon was observed when the oxidation of $1 \%$ toluene was performed. When the reactor temperature gradually increased and reached the ignition point, it jumped to $250-300^{\circ} \mathrm{C}$ within a few minutes and remained the same for several hours even after the furnace was turned off. It seemed that the heat of oxidation was enough to maintain the reactor temperature in our system. The ignition temperature was found near $160^{\circ} \mathrm{C}$ and toluene was completely oxidized. In order to protect the $\mathrm{Pt} / \mathrm{SDB}\left(<160^{\circ} \mathrm{C}\right)$ during experiments, both high flow rate and the low concentration of toluene were exercised to avoid such phenomenon.

Figs. 8 and 9 show the conversions of toluene oxidation on $\mathrm{Pt} / \mathrm{SDB}, \mathrm{Pt} / \mathrm{AC} 01$ and $\mathrm{Pt} / \mathrm{AC} 03$ under two different toluene concentrations. The performance of $\mathrm{Pt} / \mathrm{SDB}$ were clearly better than those of $\mathrm{Pt} / \mathrm{AC} 01$ and $\mathrm{Pt} / \mathrm{AC} 03$. The toluene of $90 \mathrm{ppm}$ was $100 \%$ oxidized by $\mathrm{Pt} / \mathrm{SDB}$ at $150^{\circ} \mathrm{C}$ while $\mathrm{Pt} / \mathrm{AC} 01$ and $\mathrm{Pt} / \mathrm{AC} 03$ required $180-200^{\circ} \mathrm{C}$ (Fig. 8). Similar situations were also observed for the oxidation of $442 \mathrm{ppm}$ toluene. The conversion was above $90 \%$ for $\mathrm{Pt} / \mathrm{SDB}$ at $150^{\circ} \mathrm{C}$ (Fig. 9). The conversions were not influenced by flow rates (VHSV) because their range might not be wide enough to show significant difference.

The total surface, metal loadings and Pt dispersion were similar between Pt/SDB and Pt/AC01 except the

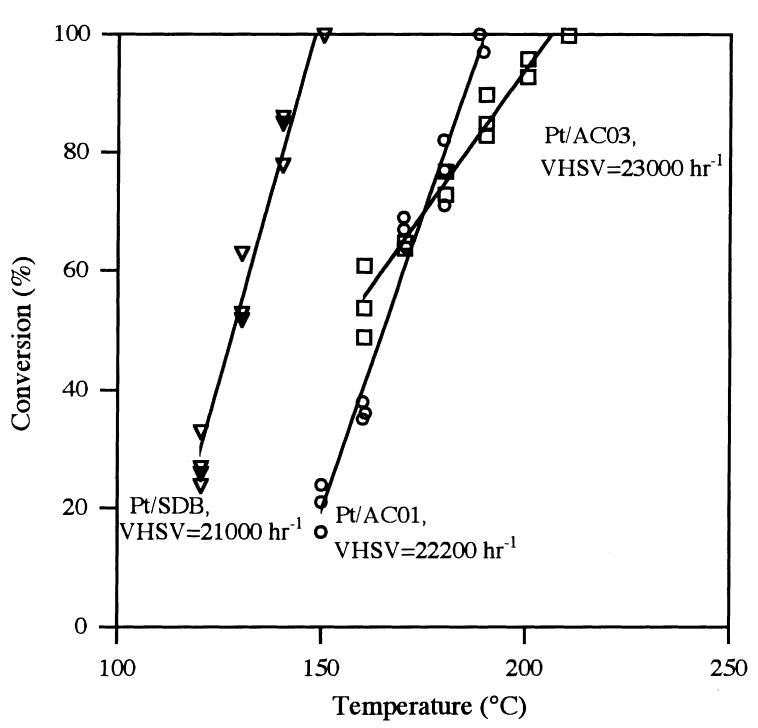

Fig. 8. Conversion of toluene oxidation ( $90 \mathrm{ppm}$ toluene/air mixture).

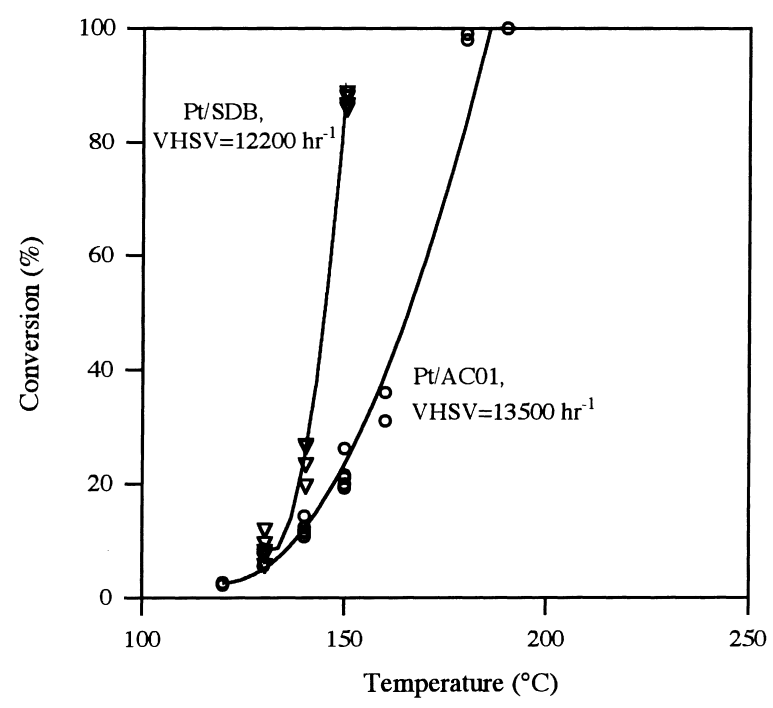

Fig. 9. Conversion of toluene oxidation (442 ppm toluene/air mixture).

hydrophobicity (Table 1). It implied that the hydrophobicity of surface should be one of the major factors influencing the activity of toluene oxidation. Water vapor generated from oxidation might be expelled from SDB surface, hence, the active sites would not be blocked. Pt/AC01 contained ash (mostly $\mathrm{Al}_{2} \mathrm{O}_{3}$ and 


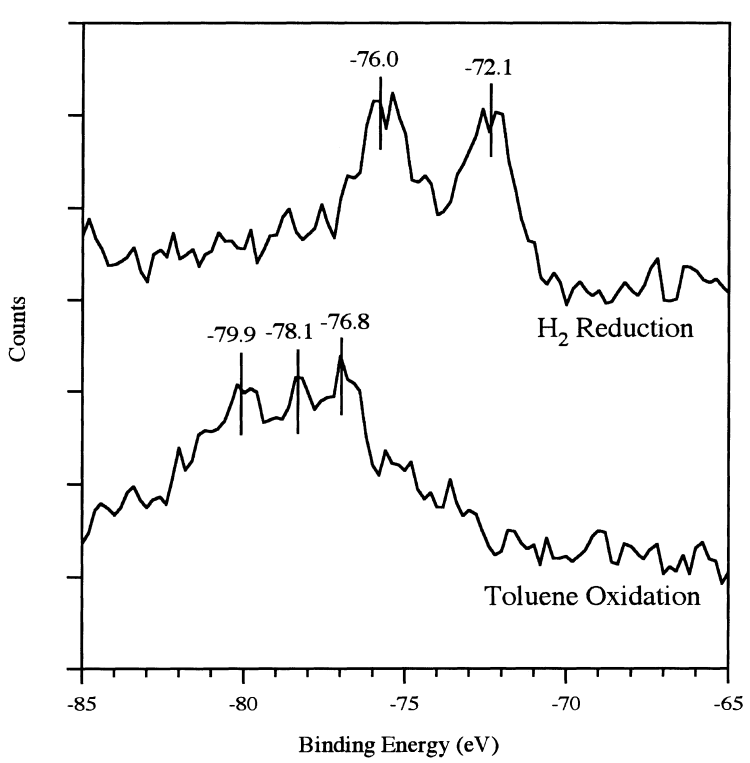

Fig. 10. Pt chemical states of Pt/AC01 by XPS.

$\mathrm{SiO}_{2}$ found by EDS) resulting less hydrophobic. The active sites of Pt/AC01 might be partially blocked by condensed water, hence, the activity was reduced. The activity of $\mathrm{Pt} / \mathrm{AC} 03$ was expected to be higher than that of Pt/AC01 because of the higher hydrophobicity (Table 1). However, their activities were found in the same range (Fig. 8). The activity of Pt/ AC03 might be depressed due to the poor Pt dispersion (Fig. 6), which counteracted the hydrophobic enhanced effect.

The chemical states of surface Pt were exhibited by XPS. Fig. 10 shows the XPS spectra of Pt/AC01 at the regime of $\mathrm{Pt} 4 \mathrm{f}_{7 / 2}$ binding energy. The binding energy of $\mathrm{Pt}^{0}$ and $\mathrm{Pt}^{\mathrm{IV}}$ are in the range $\sim 71 \mathrm{eV}$ and $73-79 \mathrm{eV}$, respectively [9]. Both $\mathrm{Pt}^{0}$ and $\mathrm{Pt}^{\mathrm{IV}}$ were found after the catalyst was reduced by hydrogen. The Pt could not be completely reduced because reduction temperature was limited to $160^{\circ} \mathrm{C}$. $\mathrm{Pt}^{0}$ was not observed after toluene oxidation suggested that active sites could be at oxidized states during reaction.

The oxidation of hydrocarbons was generally thought to occur via a surface redox cycle known as the Mars-van Krevelen mechanism. The active sites of catalyst were first oxidized by oxygen, followed by the oxidation of hydrocarbons. The mechanism could be summarized as the following two simple steps
Table 2

Kinetic constants of toluene oxidation

\begin{tabular}{|c|c|c|c|c|c|c|}
\hline \multirow{2}{*}{$\begin{array}{l}\text { Temperature } \\
\left({ }^{\circ} \mathrm{C}\right)\end{array}$} & \multicolumn{3}{|c|}{$\mathrm{Pt} / \mathrm{SDB}$} & \multicolumn{3}{|c|}{$\mathrm{Pt} / \mathrm{AC} 01$} \\
\hline & $k_{\mathrm{RH}}$ & $k_{0}$ & $k_{\mathrm{RH}} / k_{0}$ & $k_{\mathrm{RH}}$ & $k_{0}$ & $k_{\mathrm{RH}} / k_{0}$ \\
\hline 130 & 19.0 & 0.023 & 826 & 7.43 & 0.0197 & 377 \\
\hline 140 & 24.4 & 0.042 & 573 & 8.55 & 0.0334 & 256 \\
\hline 150 & 26.3 & 0.065 & 399 & 19.40 & 0.0592 & 327 \\
\hline
\end{tabular}

$\mathrm{O}_{2}+$ reduced sites $\stackrel{k_{0}}{\rightarrow}$ oxidized states

$\mathrm{RH}+$ oxidized states $\stackrel{k_{\mathrm{RH}}}{\longrightarrow}$ reduced sites $+\mathrm{H}_{2} \mathrm{O}+\mathrm{CO}_{2}$

where RH represents hydrocarbons. This mechanism resulted in a rate expression of the form,

$r_{\mathrm{RH}}=\frac{k_{0} k_{\mathrm{RH}} C_{0} C_{\mathrm{RH}}}{k_{0} C_{0}+\nu k_{\mathrm{RH}} C_{\mathrm{RH}}}$,

where $\nu$ is the stoichiometric coefficient of oxygen in the overall reaction, i.e. $\nu=9$ for toluene. The concentration of oxygen $\left(C_{0}\right)$ was much higher than that of toluene in our study. Therefore, $k_{0} C_{0}$ can be assumed constant. So Eq. (3) can be expressed as

$\frac{1}{r_{\mathrm{RH}}}=\frac{1}{k_{\mathrm{RH}} C_{\mathrm{RH}}}+\frac{\nu}{k_{0} C_{0}}$.

The $k_{\mathrm{RH}}$ and $k_{0}$ can be estimated from slope and intercept from the plots of $\left(1 / r_{\mathrm{RH}}\right)$ and $\left(1 / C_{\mathrm{RH}}\right)$, respectively. Table 2 list the results of $k_{\mathrm{RH}}$ and $k_{0}$, and their ratio. The $k_{\mathrm{RH}} / k_{0}$ ratios of $\mathrm{Pt} / \mathrm{SDB}$ were higher than those of Pt/AC01 indicated that the rate of Eq. (2) was enhanced. It was suggested that the fast water desorption on the highly hydrophobic supports made the Eq. (2) favorable to the right-hand side, especially at low temperature. Thus hydrophobic catalyst gave higher overall oxidation rate.

\section{Conclusion}

The catalytic destruction of VOC from industrial contaminants was one of the air pollution control processes. Traditionally, the catalyst supports were metal oxides, such as alumina. They were widely available and thermally stable. However, the activity could be influenced by moisture due to their hydro- 
philic surface. This study showed that hydrophobicsupported Pt catalysts gave complete oxidation of toluene at much lower temperatures. Pt/SDB showed higher oxidation activity than those of Pt/AC01 and Pt/ AC03. It implied that the hydrophobicity of supports could play an important role. Redox mechanism suggested that the oxidation of hydrocarbons might be enhanced by expelling water from catalyst surface. The sintering of Pt clusters seemed to be severe on $\mathrm{SDB}$, that would require further investigation. The only drawback of SDB was the poor thermal stability $\left(<200^{\circ} \mathrm{C}\right)$. However, the applications of hydrophobicsupported catalysts are worth exploring for their unique catalytic property.

\section{Acknowledgements}

The authors acknowledge the financial support from the National Science Council, Taiwan, Republic of China under the project number NSC-86-2214-E-002-
016. Special thanks to K.T. Chuang for supplying SDB polymer.

\section{References}

[1] J.J. Spivey, Ind. Eng. Chem. Res. 26 (1987) 2165.

[2] L.L. Hegedus, S.H. Oh, K. Baron, AIChE J. 23 (1977) 632.

[3] F. Deverino, J. Laine, Ind. Eng. Chem. Res. Dev. 22 (1983) 396.

[4] K.T. Chuang, B. Zhou, S. Tong, Ind. Eng. Chem. Res. 33 (1994) 1680.

[5] K.T. Chuang, S. Cheng, S. Tong, Ind. Eng. Chem. Res. 31 (1992) 2466.

[6] H.A. Rangwala, S.E. Wanke, F.D. Otto, Can. J. Chem. Eng. 72 (1994) 296.

[7] J.D. Weaver, E.L. Tasset, W.E. Fry, in: J.W. Ward (Ed.), Catalysis 1987, Elsevier, Amsterdam, 1988, p. 483.

[8] U. Bröckel, F. Löffler, Part. Part. Syst. Charact. 8 (1991) 215.

[9] J.F. Moulder, W.F. Stickle, P.E. Sobol, K.D. Bomben, Handbook of Photoelectron Spectroscopy, Physical Electronics Inc. 1995. 